\title{
ERRATUM TO: MELANISM AS A POTENTIAL THERMAL BENEFIT IN EASTERN FOX SQUIRRELS (SCIURUS NIGER)
}

\author{
Amanda K. Ciurej ${ }^{1}$, Ashley Oblander ${ }^{1}$, Andrew W. Swift ${ }^{2}$, And James A. Wilson ${ }^{1}$ \\ ${ }^{I}$ Department of Biology and 2Department of Mathematics, University of Nebraska at Omaha, \\ 6001 Dodge Street, Omaha, NE 68182-0040, USA
}

Erratum to: https://doi.org/10.2478/eje-2019-0013

The original publication of the article has been erroneously printed with incorrect figure 4 . The corrected version is listed below.

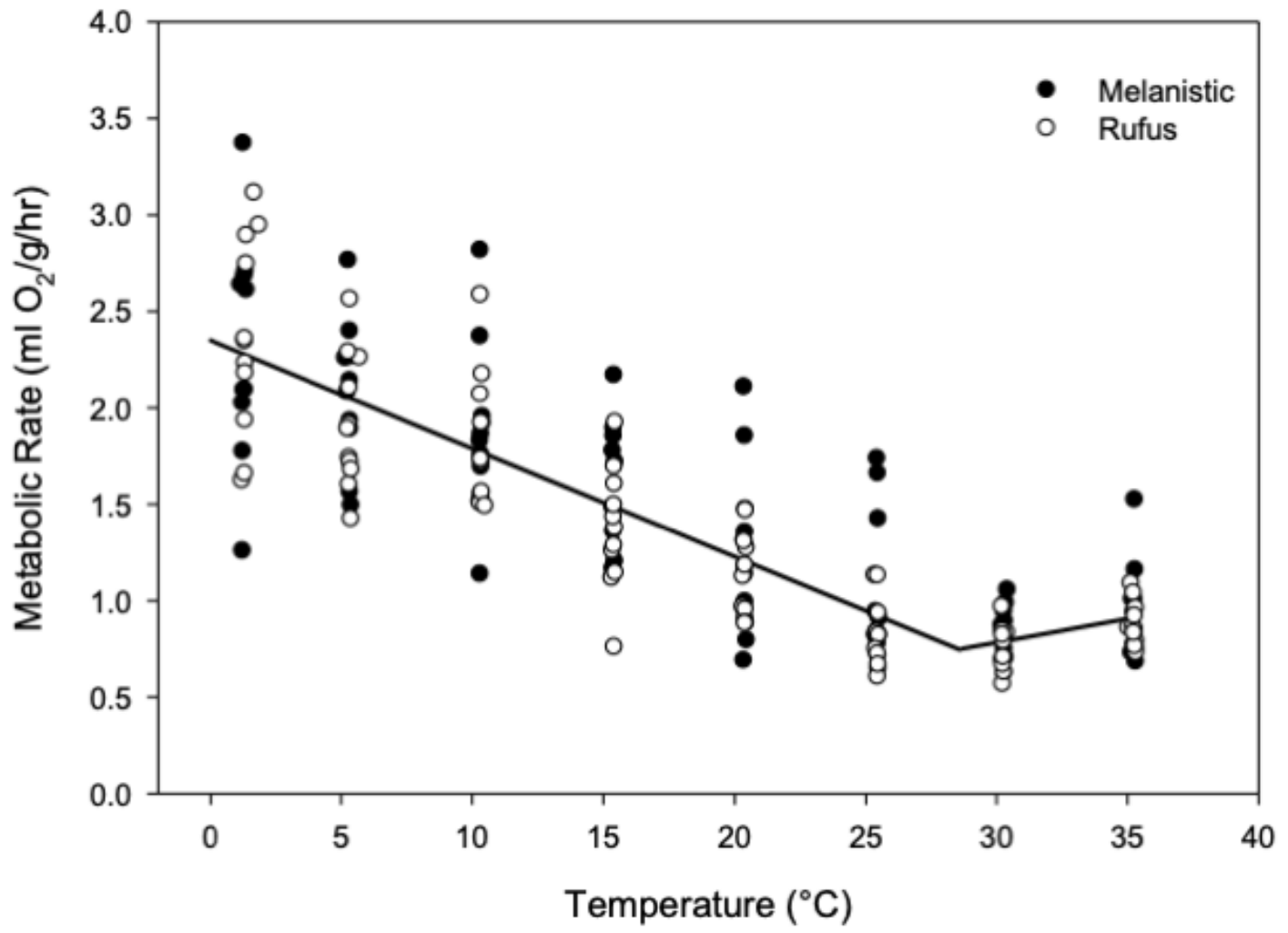

Figure 4. Rate of metabolism (black line) of rufus (open circles) and melanistic (closed circles) fox squirrels as a function of temperature with a lower critical temperature of $28.6^{\circ} \mathrm{C}$. 